\title{
Psychomotor development index in children younger than 6 years from Argentine provinces
}

\author{
Horacio Lejarraga, M.D. ${ }^{a}$, Diana M. Kelmansky, M.D. and PhD in Mathematics ${ }^{b}$, \\ Alicia Masautis, B.S. ${ }^{c}$ and Fernando Nunes, M.D. ${ }^{d}$
}

\begin{abstract}
Objective. To obtain a psychomotor development index (PDI) for each Argentine province.

Population and methods. Using a national, probabilistic, and stratified sample of 13323 male and female children younger than 6 years selected for the National Survey on Nutrition and Health (Encuesta Nacional de Nutrición y Salud, ENNyS 2004), we estimated the PDI per province based on compliance with 10 developmental milestones. The median age at attainment (median age) of each milestone was estimated adjusting a logistic regression. The PDI was estimated as $100^{*}(1+b)$, where " $\mathrm{b}$ " is the regression coefficient of $y=a+b x$, where " $y$ " is the median age as per the national reference $(\mathrm{x})$ minus the median age at attainment of a milestone. The theoretical value expected for the PDI was 100.

Results. The PDI per province ranged between 72.1 and 106.4. Most provinces showed a negative regression coefficient, which indicated a progressive increase of the delay in the age at attainment of milestones. The correlation coefficient between the PDI per province and infant mortality in 2005 was extremely high: -0.85 , suggesting that both indicators share similar biological and social determinants. The PDI was negative because the higher the mortality, the lower the PDI.

Conclusion. We have now a positive health indicator availablein Argentina: the psychomotor development index, which is a low-cost, easy to collect, and reliable tool that may be used in national health statistics.

Keywords: psychomotordevelopment, developmental tempo, environment.
\end{abstract}

http: / / dx.doi.org/10.5546/ aap.2018.eng.e251

E-mail address:

Horacio Lejarraga,

M.D.: cursotesis07@

gmail.com

Funding:

This study was completely funded by the Matanza-Riachuelo River Basin Authority (ACUMAR).

Conflict of interest:
None.

Received: 14-06-2017

Accepted: 12-09-2017

\section{INTRODUCTION}

For some time now, the need to use positive indicators to describe the general health status of the entire covered population has been posed at a country level, ${ }^{1-2}$ among academic groups $^{3}$ and international organisms. ${ }^{4}$ In the case of children, emphasis has been placed on physical growth, which describes the nutritional and health status of population groups in a very reliable manner. ${ }^{1-5}$ Although attempts have been made to measure psychomotor development as a positive indicator ${ }^{4}$ until recently, there were no adequate methods available for use in the public health field. The availablity of information on child development in the surveys carried out in the Matanza-Riachuelo River Basin on population with high proportion of families with unsatisfied basic needs (NBI) ${ }^{6}$ made it possible the preparation of a method for assessing child development in population groups (Developmental Index). ${ }^{7}$ We could also study the relation to other psychomotor development indicators and to some environmental variables so that we could enhance our knowledge on how environment influences development in the first years of life in disadvantaged areas. ${ }^{6}$ The 2005 National Survey on Nutrition
To cite: Lejarraga H, Kelmansky D, Masautis A, et al. Psychomotor development index in children younger than 6 years from Argentine provinces. Arch Argent Pediatr 2018;116(2):e251-e256. and Health (Encuesta Nacional de Nutrición y Salud, ENNyS) ${ }^{8}$ included data on development that helped to estimate a development index (DI) that had been prepared in advance. ${ }^{7}$

The objective of this study was to describe the results of this DI at a provincial and a national level and its relationship to other infant health indicators in a probabilistic sample that was representative of children younger than 6 years from 
across the country. No references were found in the bibliography regarding such important information about Argentina.

\section{MATERIAL AND METHODS}

\section{Sample}

The sample was that selected by the Ministry of Health for the 2005 ENNyS together with the ENNyS teams, under specific sampling criteria, and considering regional and national information domains, ${ }^{8}$ with probabilistic provincial samples. The distribution of children aged 6 months to 5 years per province enabled us to estimate the median age at attainment of most milestones.

The authors of this study did not participate in sample design or data collection; however, they conducted a secondary data analysis, i.e., based on an already prepared and consolidated database.

\section{Developmental milestones and estimation of the median age at attainment}

Using an instructions manual, survey takers assessed each child for attainment of the following developmental milestones (median age at attainment as per the national reference [NR] is shown in days old between parentheses): ${ }^{9}$ smiles responsively (33 days), searches for sound with the eyes (142), head steady (33), searches an object (226), pincer grasp (277), walks well (376), daytime bladder control (767), combines words (693), completes phrase (829), recognizes three colors (1209), heel-to-toe walk (1318), copies a cross (1340), draws person 6 parts (1534).(1534). The reason for such selection was that there were previous studies available on its relationship with biological and social determinants of health. ${ }^{6,10}$ The first three milestones, which are attained in the first months of life, were removed due to defects in the assessment technique during the ENNyS. The rest of the milestones are attained as of 9 months old and up to 5 years old, which was the period assessed in this study.

\section{Estimation of the median age at attainment}

The median $\left(50^{\text {th }}\right.$ percentile) age at attainment of each milestone was estimated for each province in accordance with the method described above. ${ }^{7}$ A reverse logistic regression was used because this was a cross-sectional sample based on the information of whether the child had or not attained the milestone at the time of observation.

\section{Estimation of the development index}

Once the median age at attainment of each milestone was obtained for each province, differences (D) between the median age at attainment of each milestone and the corresponding median age of the NR were estimated. ${ }^{9}$ Such differences were plotted against the age at attainment as per the NR. In all studied provinces, a high linear association was observed between such differences (D) and the corresponding age as per the NR. For this reason, a scatter plot of the differences (D) and the corresponding ages as per the NR (" $x$ ") was done for each province; then, a regression line was adjusted as per $\mathrm{D}=\mathrm{a}+\mathrm{b} \mathrm{x}$, where " $\mathrm{D}$ " was the difference between the age at attainment of each milestone among studied children and the age of the NR, " $x$ " was the median age at attainment as per the NR, and " $b$ " was the regression coefficient (slope of the line), i.e., the developmental trend (DT). ${ }^{7}$

\section{RESULTS}

The final sample size was 13323 children, of whom, 6536 were girls. Twenty-four girls and 34 boys whose chronological age was lacking were eliminated. Table 1 shows the number of children per age group, sufficient to make planned estimations. Table 2 shows the number of children per province, adequate for the adjustment of logistic regression curves for each milestone.

The extent of data adjustment to the logistic model in order to estimate the median age per province was assessed using the HosmerLemeshow test. ${ }^{11}$ No adequate adjustment was achieved in any province for one milestone (daytime bladder and bowel control).

Once the median age at attainment of milestones in each province was estimated, the differences between these and the ages of the

TABLE 1. Sample size by age

\begin{tabular}{lcc} 
Age (years old) & Girls & Boys \\
\hline $0.75-0.99$ & 1026 & 1089 \\
$1.0-1.99$ & 2105 & 2131 \\
$2.0-2.99$ & 859 & 926 \\
$3.0-3.99$ & 870 & 895 \\
$4.0-4.99$ & 875 & 937 \\
$5.0-5.99$ & 801 & 809 \\
No age data & 24 & 34 \\
\hline Total: 13381 & 6560 & 6821 \\
\hline
\end{tabular}


NR were plotted. Most provinces showed a downward trend (delay) in the age at attainment of milestones compared to the NR.

Figure 1 shows the example of a jurisdiction.

As age increases, the age at attainment of milestones shows an increasing delay. If a regression line is adjusted to these values, such trend is quantified by the " $b$ " slope, which corresponds to the delay in days for each day that the age in the NR increases. In this example, the " $b$ " slope is negative and high (-0.22).

If no developmental delay was observed in a specific area, the adjustment of differences would result in a horizontal line, whose slope would be null (equal to zero), as described in Figure 2, which shows the differences in another jurisdiction. Here, the regression line is horizontal and the slope is zero; this means that there is no delay in this specific jurisdiction.

Having adjusted a regression line for each province, Table 3 shows the regression coefficients by jurisdiction together with the confidence intervals and the DIs estimated using the following formula: $\mathrm{DI}=100 \times(1+b)$.

TABLE 2. Sample size by jurisdiction

\begin{tabular}{lccc}
\hline & Girls & Boys & Total \\
\hline 1 & 380 & 421 & 801 \\
2 & 695 & 721 & 1416 \\
3 & 204 & 221 & 425 \\
4 & 272 & 268 & 540 \\
5 & 291 & 297 & 588 \\
6 & 272 & 304 & 576 \\
7 & 213 & 201 & 414 \\
8 & 271 & 291 & 562 \\
9 & 282 & 301 & 583 \\
10 & 221 & 214 & 435 \\
11 & 200 & 193 & 393 \\
12 & 216 & 219 & 435 \\
13 & 328 & 347 & 675 \\
14 & 270 & 292 & 562 \\
15 & 193 & 196 & 389 \\
16 & 189 & 226 & 415 \\
17 & 191 & 225 & 416 \\
18 & 376 & 415 & 791 \\
19 & 379 & 383 & 762 \\
20 & 178 & 220 & 398 \\
21 & 306 & 245 & 551 \\
22 & 220 & 211 & 431 \\
23 & 215 & 208 & 423 \\
24 & 198 & 202 & 400 \\
\hline Total & 6560 & 6821 & 13381 \\
\hline & & &
\end{tabular}

A major variation among provinces, of approximately $34 \%$, was observed according to DIs. The lowest DI was 72.1, and the highest one, 106.4. It is worth noting that 4 provinces had a positive coefficient, although it was not

FIGURE 1. Differences in the age at attainment of developmental milestones between the sample from a province and the national reference ( $Y$ axis), plotted against the age at attainment as per the national reference ( $X$ axis)

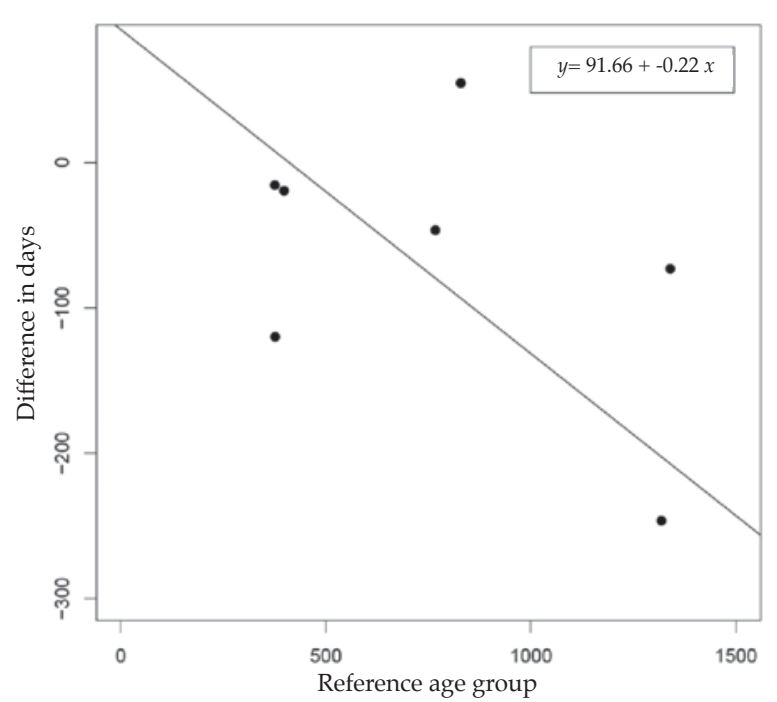

A decreasing trend is observed with age (-0.22).

FIGURE 2. Differences in the age at attainment of developmental milestones between the sample from a jurisdiction and the national reference ( $Y$ axis), plotted against the age at attainment as per the national reference (X axis)

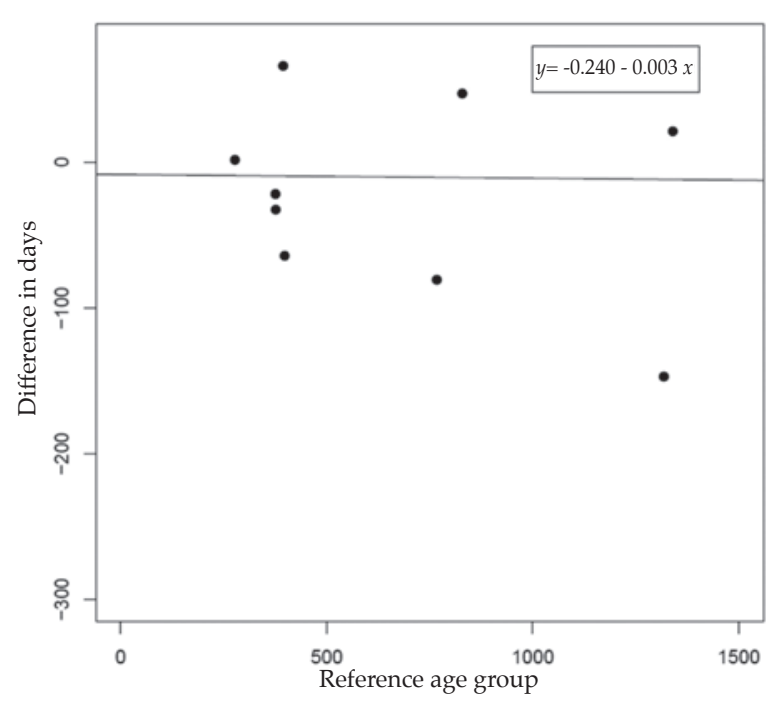

No clear trend was observed with age. The adjusted line shows a practically null slope (-0.003). 
statistically significant. A negative slope was observed in 21 out of the 24 studied provinces. In 5 of these, the slopes were statistically significant $(p<0.05)$, which means there is a delay compared to the NR. In summary, most provinces showed a progressive developmental delay; in some, such delay was not only significant but highly relevant, with an average index below 80 .

The national average is 92.6 , almost 8 points below the expected value (100).

Based on the assumption that these indices may be somehow related to the infant health status in each province, the correlation coefficient between DIs and infant mortality (IM) was estimated ${ }^{12}$ for each province for the year the ENNyS was administered (2005); 8 the resulting " $\mathrm{r}$ " value was -0.85. In 2004, the " $r$ " value was -0.79 .

The highest linear association with IM was obtained in 2005, and the lowest association, in 2013 (r: -0.53), which is more distant from 2005.

TABLE 3. Regression coefficients, 95\% confidence intervals, and development index per province

\begin{tabular}{|c|c|c|c|c|}
\hline \multirow[b]{2}{*}{ Jurisdiction } & \multirow[b]{2}{*}{$\begin{array}{c}\text { Coeficient } \\
b\end{array}$} & \multicolumn{2}{|c|}{ Confidence interval } & \multirow[b]{2}{*}{ ID } \\
\hline & & $\begin{array}{l}\text { Lower } \\
\text { límit }\end{array}$ & $\begin{array}{l}\text { Upper } \\
\text { límit }\end{array}$ & \\
\hline Capital Federal & -0.003 & -0.141 & 0.136 & 99.7 \\
\hline Buenos Aires & -0.062 & -0.200 & 0.076 & 93.8 \\
\hline Catamarca & $-0.199^{*}$ & -0.365 & -0.033 & 80.1 \\
\hline Córdoba & -0.009 & -0.172 & 0.155 & 99.1 \\
\hline Corrientes & -0.253 & -0.537 & 0.030 & 74.7 \\
\hline Chaco & $-0.279^{*}$ & -0.488 & -0.071 & 72.1 \\
\hline Chubut & 0.020 & -0.114 & 0.154 & 102.0 \\
\hline Entre Ríos & -0.047 & -0.185 & 0.092 & 95.3 \\
\hline Formosa & -0.223 & -0.461 & 0.015 & 77.7 \\
\hline Jujuy & -0.135 & -0.372 & 0.102 & 86.5 \\
\hline La Pampa & -0.015 & -0.115 & 0.085 & 98.5 \\
\hline La Rioja & -0.112 & -0.273 & 0.050 & 88.8 \\
\hline Mendoza & $-0.108^{*}$ & -0.209 & -0.007 & 89.2 \\
\hline Misiones & -0.154 & -0.338 & 0.030 & 84.6 \\
\hline Neuquén & -0.071 & -0.241 & 0.099 & 92.9 \\
\hline Río Negro & 0.052 & -0.098 & 0.203 & 105.2 \\
\hline Salta & -0.067 & -0.265 & 0.130 & 93.3 \\
\hline San Juan & $-0.178^{*}$ & -0.308 & -0.048 & 82.2 \\
\hline San Luis & $-0.188^{*}$ & -0.300 & -0.075 & 81.2 \\
\hline Santa Cruz & -0.020 & -0.136 & 0.095 & 98.0 \\
\hline Santa Fe & 0.036 & -0.084 & 0.156 & 103.6 \\
\hline Sgo. Del Estero & -0.155 & -0.355 & 0.045 & 84.5 \\
\hline Tucumán & -0.125 & -0.301 & 0.050 & 87.5 \\
\hline Tierra del Fuego & 0.064 & -0.133 & 0.260 & 106.4 \\
\hline \multicolumn{5}{|c|}{ Weighted index } \\
\hline \multicolumn{2}{|c|}{ Total for the country: } & & 92.6 & \\
\hline
\end{tabular}

${ }^{*} \mathrm{p}<0.05$.

\section{DISCUSSION}

The method proposed to estimate and summarize development in a population has been explained in a previous study ${ }^{6}$ that discussed the overall developmental quotient; however, using the DI was considered more adequate for this study, which was obtained based on the " $b$ " slope: $\mathrm{DI}=100 \times(1+\mathrm{b})$. For example, in Jujuy, the slope of the line is -0.135 ; so the equation would be $\mathrm{DI}=100 \times(1+-0.135)=100 \times(1-0.135)=86.5$. This means that the overall development of children in this province is $86.5 \%$ from the NR, i.e., they attain developmental milestones at an age that is in average- $13.5 \%$ later than that of children in the NR. Knowing the " $a$ " and " $b$ " coefficients of the adjusted line $(y=a+b x)$, it is possible to estimate the DI at any age. However, the DT indicates the differences between the median age at attainment of milestones in the sample and as per the NR, as age increases, and is directly expressed by the " $b$ " coefficient of the adjusted line. In the example for jurisdiction 10 , the DT is -0.135 ; this means that a child has a delay (negative result) of 0.135 days for each day passed in the age at attainment in relation to the NR. This is a dynamic indicator.

In the previous study, ${ }^{7}$ the regression lines were estimated including the milestones that were attained in the first year of life (social smile, etc.), whereas in this study, only those attained as of 9 months old were included. As it is known that development in the first months of life is normal in all studied groups, and does not differ from the NR, the slope of the line obtained in this study is steeper and, therefore, indices are somewhat higher. However, this does not hinder, for this study, the comparison of indices among provinces.

In this study, the DI was estimated in children younger than 6 years based on the extent of compliance of few developmental milestones in the first years of life; results were consistent because they follow the same pattern regularly in all provinces when compared to the NR. ${ }^{9}$ Behavior was also consistent with other development indicators and other infant health outcome measures. ${ }^{6}$ The correlation with IM was -0.85 , which is very high and gives grounds for presuming that both indicators share biological and social determinants.

The biggest hurdle in data adjustment was that related to the daytime bladder and bowel controlmilestone, which was also encountered when preparing the percentiles used in the NR. ${ }^{9}$ The reason for this is considered to be that the 
age at attainment of this milestone has, as a characteristic, a markedly asymmetric distribution with a long tail towards the right. It is worth noting that, in these cases, the $50^{\text {th }}$ percentile (used to estimate the index) is the less affected value by such adjustment hurdle.

In our first study, ${ }^{7}$ the indicator was defined as a "quotient" but it should have been more properly called "index".

Two reliable studies on development have been conducted in the Argentine population. ${ }^{12,13}$ One was based on the assessment of development using the National Screening Test (Prueba Nacional de Pesquisa, PRUNAPE), a national, duly validated, highly sensitive and specific test; this study found that $15 \%-48 \%$ of children had developmental disorders. This was dependent on the socioeconomic level of the study population, ${ }^{6,13}$ evidenced by the $15 \%$ of developmental disorders observed in the highest social strata. ${ }^{14}$ Based on these data and the 92.6 overall DI for Argentina established in this study (almost 8 points below the expected value), it may be stated that psychomotor development delay, when compared to other health problems at a national level, is one of the most important infant health problems in our country. Because of this, it is more than necessary to have an indicator for population groups.

This indicator depicts an alarming disparity among provincial values because it denotes a regional inequality in development. The correlation coefficient of -0.84 between the DI and IM in each province confirms that both indicators share similar determinants. In the past, the correlation coefficient between adult height of 18-year-old youth and social and health outcome measures was studied and showed values of -0.60 and -0.62 compared to IM rates in the 1-4 year old group and the percentage of families with UBNs in each province, respectively. ${ }^{1}$ Such associations reinforce the idea that positive health indicators of physical growth and psychomotor development not only reflect growth and development, respectively, but also describe how biological and social determinants affect children's health. Results show a serious inequality in development among provinces but are based on a survey administered in 2005. In 2017, results may be different. It would be very important to update these data, compare them over time, establish a relationship with health determinants, and interpret them in the broader context of each province.
The usefulness of having a DI as a positive indicator in the first years of life is really important considering that whenever a country wishes to know psychomotor development, it has to conduct an investigation to choose a test. Such strategy requires conducting a survey, selecting a test, training staff, and, sometimes, paying copyright fees, all of which takes too much time. However, the indicator developed in this study uses locally validated milestones and requires minimum training, data collection in the field takes little time, and the indicator may be implemented as part of the routine health care process in the country without resorting to a survey. It is time for health law enforcement bodies to include infant growth and development as positive indicators. There are indicators, methods to obtain them, and mathematical techniques to process them currently available. It will be necessary to use them in the long term and establish a relationship with the context, which will help to consolidate their meaning in the field of health.

\section{REFERENCES}

1. Lejarraga H. El crecimiento físico como indicador de salud y bienestar socioeconómico de la población. In: INDEC. Infanciay condiciones devida: Encuestaespecial parael diagnóstico y la evaluación de las metas sociales. Buenos Aires: INDEC; 1995.P.101-128.

2. Iannotti RJ, Kogan MD, Janssen I, et al. Patterns of Adolescent Physical Activity, Screen-Based Media Use, and Positive and Negative Health Indicators in the U.S. and Canada. J Adolesc Health 2009;44(5):493-9.

3. Schlaepfer-Pedrazzini L, Infante-Castañeda C. La medición de la salud: perspectivas teóricas y metodológicas. Salud Pública Mex 1990;32(2):141-55.

4. WHO Multicentre Growth Reference Study Group. WHO Motor Development Study: windows of achievement for six gross motor development milestones. Acta Paediatr Suppl 2006;450:86-95.

5. Tanner JM. Growth as a mirror of the condition of society; secular trends, and class distinctions. In: Dubuc MB, Demirdjian A, eds. Human growth: a multidisciplinary review. London: Taylor and Francis; 1986.P.3-34.

6. Lejarraga H, Masautis A, Kelmansky D, et al. Desarrollo psicomotor infantil en la Cuenca Matanza Riachuelo: pesquisa de problemas inaparentes del desarrollo. Rev Argent Salud Pública 2014;5(19):17-24.

7. Lejarraga H, Kelmansky D, Pascucci MC, et al. Evaluación del desarrollo psicomotor del niño en grupos de población como indicador positivo de salud. Arch Argent Pediatr 2016;114(1):23-29.

8. Ministerio de Salud. Encuesta Nacional de Nutrición y Salud ENNyS. Documento de Resultados. Buenos Aires: Ministerio de Salud; 2007. [Accessed on: October $3^{\text {rd }}$, 2017]. Available at: http://www.msal.gob.ar/images/stories / bes / graficos / 0000000257 cnt-a08-ennys-documento-deresultados-2007.pdf

9. Lejarraga H, Krupitzky S, Kelmansky D, et al Edad de cumplimiento de pautas de desarrollo en niños argentinos 
e256 / Arch Argent Pediatr 2018;116(2):e251-e256 / Original article

menores de seis años argentinos. Arch Argent Pediatr 1996;94(6):355-67.

10. Lejarraga H, Pascucci MC, Krupitzky S, et al. Psychomotor development in Argentinean children aged 0-5 years. Paediatr Perinat Epidemiol 2002;16(1):47-60.

11. Hosmer DW, Lemeshow S. Applied logistic regression. New York: Wiley; 1989.

12. UNICEF. Sociedad Argentina de Pediatría. Salud maternoinfanto-juvenil en cifras. 2006. [Accessed on: October $3^{\text {rd }}$, 2017]. Available at: http://www.bvspediatria.org.ar/ smij2006.pdf

13. Lejarraga H, Menéndez A, Menzano E, et al. PRUNAPE: Pesquisa de trastornos de desarrollo en el primer nivel de atención. Arch Argent Pediatr 2008;106(2):119-25.

14. Lejarraga $H$, Menéndez A, Menzano E, et al. Screening for developmental problems at primary care level: a field programme in San Isidro, Argentina. Paediatr Perinat Epidemiol. 2008;22(2):180-7. 